\title{
An Enrichment Technique for Auxotrophs of Agrobacterium tumefaciens using a Combination of Carbenicillin and Lysozyme
}

\author{
By P. M. KLAPWIJK, A. J. R. DE JONGE, R. A. SCHILPEROORT \\ AND A. RORSCH \\ Department of Biochemistry, The University, \\ Leiden, The Netherlands
}

(Received 5 May 1975)

SUMMARY

\begin{abstract}
A procedure to enrich for auxotrophic and fermentation mutants of Agrobacterium tumefaciens is described. The method is based on the amplification of the killing power of carbenicillin by the addition of lysozyme. Isolation frequencies of some types of mutants are presented, with and without the application of the proposed procedure. The yield of mutants is usually enhanced a hundredfold per enrichment treatment.
\end{abstract}

\section{INTRODUCTION}

The Gram-negative soil bacterium Agrobacterium tumefaciens (Smith \& Townsend) Conn. has been the subject of research because it can induce tumours on dicotyledonous plants. To analyse the bacterial functions involved in tumour induction, a genetic system has to be developed and specific mutants have to be isolated. To isolate such mutants routinely a selection technique is needed. An enrichment technique for $A$. tumefaciens using D-cycloserine was described by Bourgin-Rosenberg, Garnier-Expert \& Tourneur (I974) but they did not indicate the degree to which the yield was enhanced.

A frequently-used method of obtaining Escherichia coli auxotrophs is based on the inhibition of wall synthesis in growing cells by the antibiotic penicillin. Prototrophs become osmotically fragile and are selectively lysed, whereas the starved auxotrophs remain unaffected (Davis, I948; Lederberg \& Zinder, 1948). The yield depends on the efficiency with which growing cells are killed and on the degree of resistance of the starved cells to the treatment. We therefore studied the survival of starved organisms during treatment with agents promoting a high killing rate in growing $A$. tumefaciens. A combination of carbenicillin and lysozyme was chosen as the selective agent.

In reconstruction experiments, the survival of growing and starved bacteria in mixed cultures was determined. The efficiency was finally investigated by determining the isolation frequencies of auxotrophic and fermentation mutants with and without the application of the selection procedure.

\section{METHODS}

Bacterial strains are listed in Table I. All incubations were carried out at $29{ }^{\circ} \mathrm{C}$.

Media. Mineral medium (SM) (Schilperoort, I969) contained (g/l): $\mathrm{K}_{2} \mathrm{HPO}_{4}, 2.05$; $\mathrm{KH}_{2} \mathrm{PO}_{4}, \mathrm{I} \cdot 45 ;\left(\mathrm{NH}_{4}\right)_{2} \mathrm{SO}_{4}, 3.00 ; \mathrm{MgSO}_{4} .7 \mathrm{H}_{2} \mathrm{O}, 0.50 ; \mathrm{NaCl}, 0.15 ; \mathrm{CaCl}_{2} .6 \mathrm{H}_{2} \mathrm{O}, 0.0 \mathrm{IO}$; and glucose, 2 ; for liquid media, $\mathrm{FeSO}_{4} \cdot 7 \mathrm{H}_{2} \mathrm{O}, 0.0025$. When glucose was replaced by 
Table I. Strains used

\begin{tabular}{lll} 
Strain & \multicolumn{1}{c}{ Properties } & \multicolumn{1}{c}{ Origin } \\
LBA2 & Wild-type A. tumefaciens B6s3 & Laboratorium voor Genetika, Gent, Belgium \\
& & (Vervliet et al. 1975) \\
LBA32 & his rif-r & A derivative of LBA2, from our laboratory. \\
& & His - by NTG mutagenesis; mutates \\
& & spontaneously to rifampicin resistance \\
LBA201 & Wild-type A. tumefaciens C58 & U.S.A. (Hamilton \& Fall, I97I)
\end{tabular}

another carbon source, the same amount was used; if necessary, L-amino acids were used at $50 \mu \mathrm{g} / \mathrm{ml}$.

Nutrient broth (NB) contained (g/1): Difco nutrient broth, 8; Difco yeast extract, 5; $\mathrm{NaCl}, 5$.

When required, the media were solidified by $\mathrm{I} \cdot 8 \%(\mathrm{w} / \mathrm{v})$ Difco Bacto-Agar. Rifampicin was added to plates to a concentration of $20 \mu \mathrm{g} / \mathrm{ml}$.

Other solutions. Citrate buffer contained $2 \mathrm{I} \cdot 0 \mathrm{~g}$ citric acid and $8.8 \mathrm{~g} \mathrm{NaOH} / 1$, and was adjusted to $\mathrm{pH} 5.5$ with $2 \mathrm{M}-\mathrm{NaOH}$ (Miller, 1972). $N$-methyl- $N^{\prime}$-nitro- $N$-nitrosoguanidine (NTG) was dissolved in citrate buffer to $\mathrm{r} \cdot 0 \mathrm{mg} / \mathrm{ml}$ just before use. Carbenicillin, cycloserine and lysozyme were dissolved in distilled water shortly before use and sterilized by filtration through $0.2 \mu \mathrm{m}$ pore-size filters.

Materials. Rifampicin, D-cycloserine, and lysozyme (egg-white, grade I) were obtained from Sigma. Carbenicillin (Pyopen) was from Beecham S.A., Heppignies, Belgium. The NTG was from Pfaltz-Bauer Inc., Flushing, New York, U.S.A.

Mutagenesis was based on the method described by Miller (1972). Overnight cultures in NB were diluted with fresh medium to an $E_{666}$ of $0 \cdot 10$ (which corresponds to approximately $2 \times 10^{8}$ organisms $/ \mathrm{ml}$ ). After growth to an $E_{666}$ of 0.4 , they were harvested by centrifugation ( $15 \mathrm{~min}, 2200 \mathrm{~g}$ ), and the pellet was washed with, and resuspended in, citrate buffer. After dilution to $E_{666}=0.10$, NTG was added to a final concentration of $200 \mu \mathrm{g} / \mathrm{ml}$. After $3 \mathrm{~h}$, when survival was approximately $3 \%$, the suspension was diluted twofold. The bacteria were collected by centrifugation and washed with, and resuspended in, SM supplemented with the appropriate growth factors. The mutagenized culture was incubated overnight to allow segregation and expression of mutations.

Enrichment procedure. The mutagenized cells in supplemented SM were collected by centrifugation, washed with and resuspended in SM to an $E_{666}$ of 0.10 , and starved for I $50 \mathrm{~min}$ with shaking. Next carbenicillin $(0 . \mathrm{Iml}$ at $10 \mathrm{mg} / \mathrm{ml})$ and lysozyme $(0 . \mathrm{I} \mathrm{ml}$ at $2 \mathrm{mg} / \mathrm{ml}$ ) were added to $\mathrm{I} \cdot 8 \mathrm{ml}$ of the culture in a $100 \mathrm{ml}$ Erlenmeyer flask. After the addition of these agents the shaking frequency was lowered to $0.5 / \mathrm{s}$ in a linear shaker with an amplitude of $2 \mathrm{~cm}$.

After $4 \mathrm{~h}$ the cells were collected by centrifugation, washed with distilled water and with SM, and resuspended in SM supplemented with the necessary growth factors. After growth to stationary phase a second identical enrichment treatment was given.

Isolation of mutants. Suitable dilutions were plated on supplemented SM agar and the number of auxotrophs was determined by replica-plating of the colonies or by streaking them on to supplemented and unsupplemented SM. 


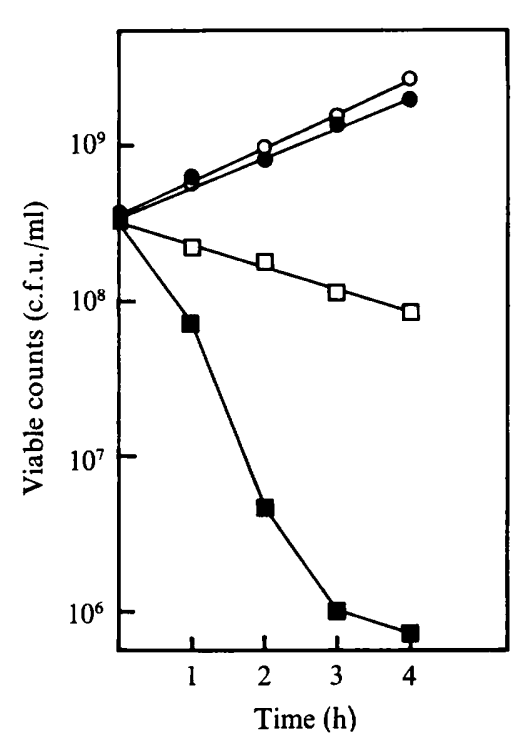

Fig. I

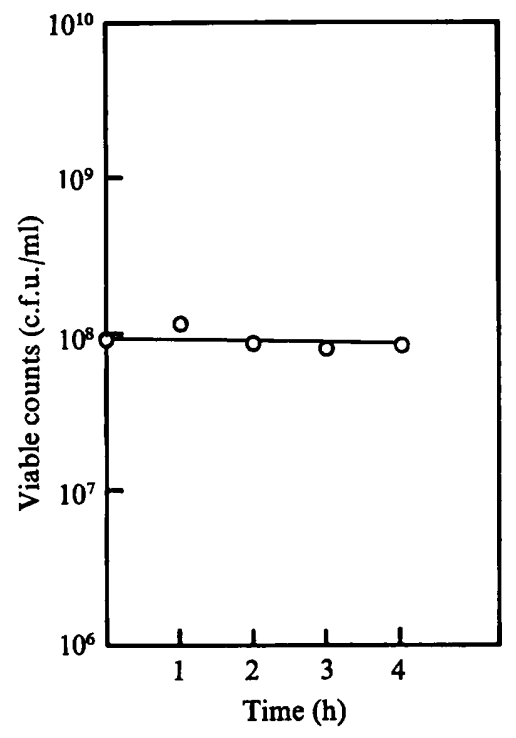

Fig. 2

Fig. I. Survival of LBA2 in SM after the addition of carbenicillin and/or lysozyme (added at time zero). $\bigcirc$, Without carbenicillin or lysozyme; 0 , with $100 \mu \mathrm{g}$ lysozyme/ml; $\square$, with $500 \mu \mathrm{g}$ carbenicillin $/ \mathrm{ml} ; \boldsymbol{\square}$, with $500 \mu \mathrm{g}$ carbenicillin and $100 \mu \mathrm{g}$ lysozyme $/ \mathrm{ml}$.

Fig. 2. Viable counts of starved LBA32 in SM with $500 \mu \mathrm{g}$ carbenicillin and $100 \mu \mathrm{g}$ lysozyme/ml (added at time zero), determined on SM supplemented with $50 \mu \mathrm{g}$ histidine $/ \mathrm{ml}$.

\section{RESULTS}

The effect of carbenicillin and lysozyme on growing and starved bacteria

Wild-type $A$. tumefaciens (LBA2) was not killed very efficiently by carbenicillin at concentrations up to $500 \mu \mathrm{g} / \mathrm{ml}$. After a $4 \mathrm{~h}$ treatment the viable count was $25 \%$ of that at zero time (Fig. I). The addition of $100 \mu \mathrm{g}$ lysozyme $/ \mathrm{ml}$ to a LBA2 culture in SM had no noticeable effect on the growth rate (Fig. I). The combination of carbenicillin plus lysozyme enhanced the killing considerably. After $4 \mathrm{~h}$ the viable count had dropped to approximately $0.2 \%$ of its value at zero time (Fig. I). Increasing the lysozyme concentration from Ioo to $1000 \mu \mathrm{g} / \mathrm{ml}$ in combination with $500 \mu \mathrm{g}$ carbenicillin $/ \mathrm{ml}$ did not change the killing substantially; therefore $100 \mu \mathrm{g}$ lysozyme $/ \mathrm{ml}$ in combination with $500 \mu \mathrm{g}$ carbenicillin $/ \mathrm{ml}$ was used in subsequent experiments.

For LBA32 (his rif-r) we found a histidine starvation period of $150 \mathrm{~min}$ was sufficient to stop growth. When the carbenicillin and lysozyme were added after this period, the viable count remained at least $90 \%$ after a $4 \mathrm{~h}$ exposure (Fig. 2).

\section{Reconstruction experiments}

To obtain information about the effect of the carbenicillin-lysozyme treatment on a mixed population of starved and growing cells, we performed reconstruction experiments with LBA2 and LBA32. Overnight cultures were washed and mixed in SM without histidine at a ratio of prototrophs to auxotrophs of approximately 1000: I. Subsequently, two enrichment treatments were given as described in Methods. During this procedure viable 

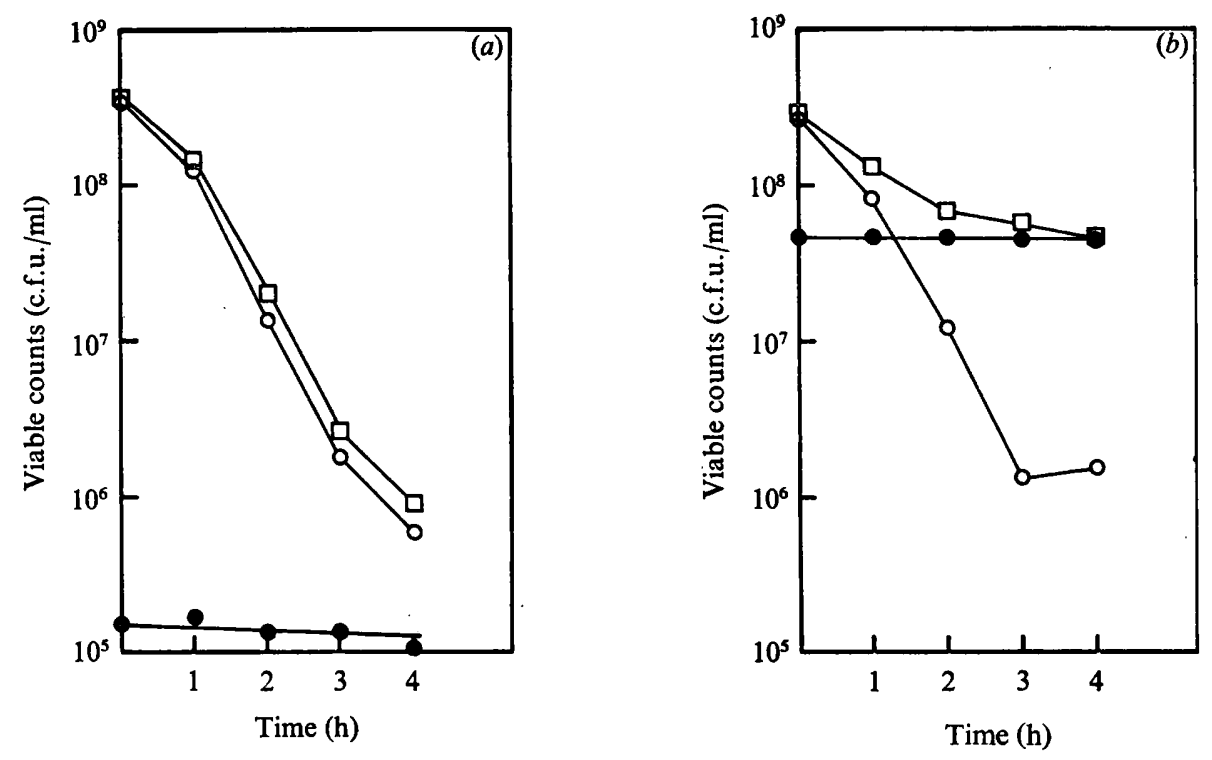

Fig. 3. Reconstruction experiment with a mixture of LBA2 and LBA32. The viable counts in two consecutive carbenicillin-lysozyme treatments, as described in Methods, were determined. (a) First treatment; (b) second treatment. $\square$, Total viable counts; O, LBA2; O, LBA32. Viable counts of LBA2 were determined on SM, of LBA32 on SM supplemented with $50 \mu \mathrm{g}$ histidine and $20 \mu \mathrm{g}$ rifampicin $/ \mathrm{ml}$, and total counts were determined on NB.

Table 2. Viable counts of $\mathrm{LBA} 2$ and $\mathrm{LBA} 32$ during a reconstruction experiment consisting of two consecutive enrichment cycles

\begin{tabular}{|c|c|c|c|c|}
\hline & \multicolumn{4}{|c|}{ Viable count (c.f.u./ml) } \\
\hline & \multicolumn{2}{|c|}{ First cycle } & \multicolumn{2}{|c|}{ Second cycle } \\
\hline & Initial & Final & Initial & Final \\
\hline LBA2 & $3.5 \times 10^{8}$ & $6.0 \times 10^{5}$ & $2.8 \times 10^{8}$ & $1.5 \times 10^{6}$ \\
\hline LBA32 & $1.5 \times 10^{5}$ & $9.5 \times 10^{4}$ & $4.6 \times 10^{7}$ & $4.4 \times 10^{7}$ \\
\hline LBA2: LBA32 & 2300: I & $7: 1$ & $6: 1$ & $0.03: 1$ \\
\hline
\end{tabular}

counts of LBA2 and LBA32 were determined on selective media (Fig. 3 and Table 2). In these experiments, LBA32 was enriched by a factor $7 \times 10^{4}$.

\section{Enrichment in mutagenized A. tumefaciens cultures}

Formerly we isolated mutants by replica-plating directly after NTG mutagenesis. In Table 3, isolation frequencies are presented of some types of auxotrophs and fermentation mutants without and after two enrichment cycles. The data indicate that the treatment gives a considerable enhancement in mutant yield, which can be estimated as a factor of $10^{4}$ after two cycles.

\section{The use of $\mathrm{D}$-cycloserine}

Reconstruction experiments using $2 \times 10^{-3} \mathrm{M}$ D-cycloserine (Miller, 1972; BourginRosenberg et al. 1974) showed that the killing of the growing prototrophs was very inefficient. After $4 \mathrm{~h}$ the viable count was $76 \%$ of the value at zero time; when $100 \mu \mathrm{g}$ lysozyme $/ \mathrm{ml}$ was also added, this was lowered to $6 \mathrm{I} \%$. The cell count of the starved auxotroph LBA32 remained above $90 \%$ in both experiments. 
Table 3. Isolation of mutants after NTG mutagenesis, without enrichment and after two enrichment cycles

\begin{tabular}{|c|c|c|c|c|c|}
\hline \multicolumn{6}{|c|}{ All results are of separate experiments. } \\
\hline & & \multicolumn{2}{|c|}{ Without enrichment } & \multicolumn{2}{|c|}{ With enrichment } \\
\hline Strain & $\begin{array}{c}\text { Selected } \\
\text { auxotrophy }\end{array}$ & $\begin{array}{c}\text { No. } \\
\text { of colonies } \\
\text { tested }\end{array}$ & $\begin{array}{l}\text { No. of } \\
\text { auxotrophs } \\
\text { isolated }\end{array}$ & $\begin{array}{l}\text { No. } \\
\text { of colonies } \\
\text { tested }\end{array}$ & $\begin{array}{c}\text { No. of } \\
\text { auxotrophs } \\
\text { isolated }\end{array}$ \\
\hline \multirow[t]{3}{*}{ LBA2 } & $\mathrm{Leu}^{-}$ & 9000 & $\mathbf{I}$ & $\begin{array}{l}100 \\
100 \\
100\end{array}$ & $\begin{array}{l}75 \\
83 \\
56\end{array}$ \\
\hline & $\mathrm{Mtl}^{-}$ & - & - & $\begin{array}{l}100 \\
100 \\
100\end{array}$ & $\begin{array}{l}18 \\
18 \\
48\end{array}$ \\
\hline & $\mathrm{Gal}^{-}$ & 8000 & 3 & - & - \\
\hline \multirow[t]{3}{*}{ LBA2OI } & $\mathrm{Leu}^{-}$ & 12000 & 9 & $\begin{array}{l}100 \\
100 \\
100\end{array}$ & $\begin{array}{l}80 \\
82 \\
84\end{array}$ \\
\hline & $\mathrm{Gal}^{-}$ & - & - & $\begin{array}{l}100 \\
100 \\
100\end{array}$ & $\begin{array}{r}100 \\
84 \\
84\end{array}$ \\
\hline & $\mathrm{Arg}^{-}$ & 12000 & $\circ$ & 300 & 120 \\
\hline
\end{tabular}

$\mathrm{Mtl}^{-}$, no utilization of mannitol; $\mathrm{Gal}^{-}$, no utilization of galactose; $\mathrm{Arg}^{-}$, requirement for arginine; $\mathrm{Leu}^{-}$, requirement for leucine.

\section{DISCUSSION}

Our results showed that it is possible to enrich for auxotrophic and fermentation mutants in A. tumefaciens to a useful degree. The efficiency of the isolation procedure was usually enhanced a hundredfold per enrichment treatment. Since there was almost the same extent of killing in the second carbenicillin-lysozyme treatment as in the first, there was no noticeable selection for resistant bacteria. As the viable count of the starved bacteria remained nearly $100 \%$, we may conclude that in the time used there was not enough cross-feeding to allow the starved bacteria to start growth and thus become susceptible to killing. This enrichment procedure should make it possible to isolate mutants after a lighter mutagenic treatment, thus lowering the chance of secondary mutations.

We consider that our results with a combination of carbenicillin and lysozyme can be explained in the light of current views on the structure of the cell wall of Gram-negative bacteria (Costerton, Ingram \& Cheng, 1974): the outer membrane is distorted, as a secondary effect of the inhibition of murein synthesis by carbenicillin, making the entry of lysozyme in the periplasmic zone possible; after sufficient lysozyme digestion the cells become sensitive to osmotic shock. This explanation is supported by the microscopic observation that, during the treatment, the cellular surface bulges in the equatorial region.

We thank Miss M. A. E. Groothuis for her technical instructions. 


\section{REFERENCES}

Bourgin-Rosenberg, M., Garnier-Expert, D. \& Tourneur, J. (I974). Obtention de mutants auxotrophes de deux souches d'Agrobacterium tumefaciens: étude de leurs propriétés vis-a-vis du phage $\Omega$. Comptes rendus hebdomadaire des séances de l'Académie des sciences 278, 279 I-2794.

Costerton, J. W., Ingram, J. M. \& Cheng, K. J. (1974). Structure and function of the cell envelope of Gram-negative bacteria. Bacteriological Reviews 38, 87-I I0.

Davis, B. D. (I948). Isolation of biochemically deficient mutants of bacteria by penicillin. Journal of the American Chemical Society 70, 4267.

Hamilton, R. H. \& FAl., M.Z. (1971). The loss of tumor-initiating ability in Agrobacterium tumefaciens by incubation at high temperature. Experientia 27, 229-230.

LEDERBERG, J. \& ZINDER, N. (1948). Concentration of biochemical mutants of bacteria with penicillin. Journal of the American Chemical Society 70, 4267-4268.

Miller, J. H. (1972). Experiments in Molecular Genetics. Cold Spring Harbor: Cold Spring Harbor Laboratories.

SCHILPEROORT, R. A. (1969). Investigations on plant tumors: crown gall. Thesis, University of Leiden, The Netherlands.

Vervliet, G., Holsters, M., Teuchy, H., Van Montagu, M. \& Schell, J. (1975). Characterization of different plaque forming and defective temperate phages in Agrobacterium strains. Journal of General Virology 26, 33-48. 